\title{
Determination of ionic conductivity in the Bi-Si-O and $\mathrm{Pb}-\mathrm{Si}-\mathrm{O}$ glasses
}

\author{
J. KARCZewski*, T. Miruszewski, B. Bochentyn, B. Kusz \\ Faculty of Applied Physics and Mathematics, Gdansk University of Technology, \\ 80-233 Gdańsk, ul. Narutowicza 11/12 Poland
}

\begin{abstract}
Impedance spectroscopy measurements in various gas atmospheres were carried out in order to explain the doubts about the type of carriers and the mechanism of electrical conductivity in $\mathrm{Bi}-\mathrm{Si}-\mathrm{O}$ and $\mathrm{Pb}-\mathrm{Si}-\mathrm{O}$ glasses. In bismuth silicate glass, a typical ionic conductivity with oxygen ions as charge carriers was observed. The level of electrical conductivity of the glass at $400{ }^{\circ} \mathrm{C}$ was $5 \times 10^{-8} \mathrm{~S} \cdot \mathrm{cm}^{-1}$, with the activation energy of $1.3 \mathrm{eV}$ and was independent of measuring atmosphere. In the case of lead silicate glasses, the conductivity changed with measuring atmosphere. Two types of charge carriers: oxygen ions and proton ions were postulated. Proton conductivity measured in wet argon at temperature $400{ }^{\circ} \mathrm{C}$ was estimated at the level of $4 \times 10^{-8} \mathrm{~S} \cdot \mathrm{cm}^{-1}$ while the oxygen ions conductivity in such conditions was $78 \times 10^{-8} \mathrm{~S} \cdot \mathrm{cm}^{-1}$. We suggest that both types of charge carriers are transported along the same conduction paths using oxygen defects in the glass structure.
\end{abstract}

Keywords: oxide glasses; ionic conductivity; proton conductors

\section{Introduction}

Lead silicate and bismuth silicate glasses were widely investigated [1-3] and a lot of industrial applications were developed due to their specific properties. The structure of these glasses has been extensively studied for many years using various experimental techniques: IR spectroscopy [4], XPS [5], EXAFS [6] etc. and very often the studies were supported by computer simulations. There are a lot of reports in the literature describing the properties of glass subjected to reduction process, carried out at elevated temperature and in a reducing atmosphere, e.g. hydrogen [7, 8]. In particular, reduction process leads to significant changes in the optical [9] and electrical properties due to the formation of a metallic layer on the surface $[10,11]$.

The electrical properties of lead silicate and bismuth silicate glasses were widely investigated in pure, unmodified systems [12, 13], and also in the systems containing additional modifiers [14, 15]. Despite many studies, the type of charge carriers participating in the process of electrical

*E-mail: jkarczew@mif.pg.gda.pl conductivity has not been clearly determined. Researches trying to explain the electrical conductivity of bismuth silicate glasses imply that the mechanism of conductivity is based on transport of oxygen ions [3]. Milnes et al. [16] claim that charge carriers in $\mathrm{Pb}-\mathrm{Si}-\mathrm{O}$ glass are lead ions, but at the same time they note that the presence of $\mathrm{OH}$ group significantly affects the resistivity value. On the other hand, Abe et al. [17] disagree with the statement that $\mathrm{Pb}^{2+}$ ions are responsible for the transport of charge carriers. They claim that the conductivity is based on the transport of protons. There are also some papers which suggest the electron conduction mechanism [18]. Thus, it can be stated that there are many contradictions in the knowledge of conductivity mechanisms in oxide glasses. Explaining the process of conductivity in oxide glasses may have a key role in understanding the process of reduction in these glasses. Production of new materials based on the reduction process of oxide glasses enjoys great interest in scientific world and still requires further analysis of this phenomenon [19-23]. The investigation may also allow to develop application areas for oxide glasses. In an attempt to explain these doubts we decided to investigate the type of carriers and 
the mechanism of electrical conductivity. For this purpose, the impedance spectroscopy measurements in various gas atmospheres were carried out. The investigation was performed for glasses with the ratio of metal atoms $(\mathrm{Bi}, \mathrm{Pb})$ to silicon atoms equal to $1: 1$. Such chemical composition of the glass should provide sufficient metal ion content and a relatively high melting point.

\section{Experimental}

Glass samples of compositions $33 \mathrm{Bi}_{2} \mathrm{O}_{3}$ $67 \mathrm{SiO}_{2}$ and $50 \mathrm{PbO}-50 \mathrm{SiO}_{2}$ (corresponding to atomic ratio of metal to silicon 1:1) have been fabricated from appropriate reagent grade oxides (Alfa Aesar, purity $>99 \%$ ) by the conventional melt quenching technique. First, the reagents were pulverized in an agate mortar and melted in a ceramic crucible at $1200{ }^{\circ} \mathrm{C}$ in air. Then, they were quenched to form glassy pellets. The obtained pellets were annealed at $420{ }^{\circ} \mathrm{C}$ for $1 \mathrm{~h}$ and cooled in a furnace with a cooling rate of $\sim 10{ }^{\circ} \mathrm{C} / \mathrm{min}$. Basing on the results of Energy Dispersive X-ray Spectroscopy measurements performed by EDAX Genesis APEX 2i with ApolloX SDD spectrometer, the final glass compositions were determined as $25 \mathrm{Bi}_{2} \mathrm{O}_{3}-75 \mathrm{SiO}_{2}$ and $44 \mathrm{PbO}-56 \mathrm{SiO}_{2}$ with a trace amount of alumina $(\sim 1$ at.\%). An example of EDS spectrum is shown in Fig. 1.

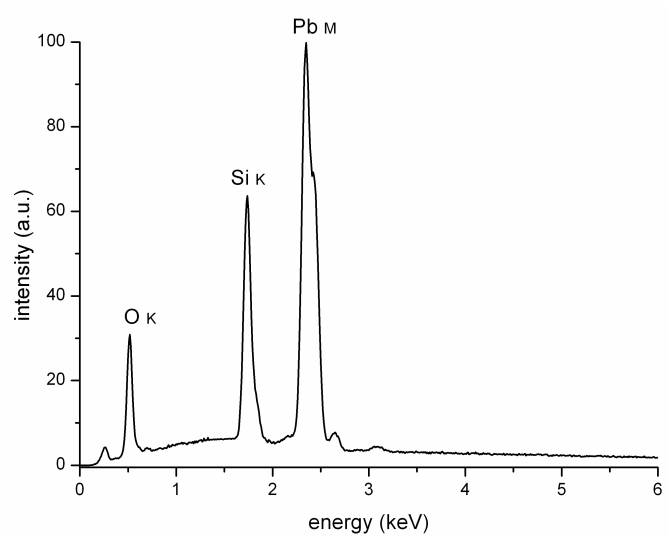

Fig. 1. The EDS spectrum of as-prepared lead-silicate glass.

As can be seen, the obtained composition differs from the nominal one by about $6 \%$. This is caused by the evaporation of metal during the synthesis of the glass. The fabricated pellets of glass (yellowish in the case of lead glass and dark brown in the case of bismuth glass) have a diameter equal to $12.5 \mathrm{~mm}$ and thickness equal to $2 \mathrm{~mm}$. The X-ray diffraction method (XRD) was used to determine the structure of investigated samples. An X'Pert Pro MPD Philips diffractometer using $\mathrm{CuK} \alpha 1.542 \AA$ radiation at room temperature was applied. Thermal analysis (Differential Scanning Calorimetry, DSC) was performed in flowing nitrogen in the temperature range from $20{ }^{\circ} \mathrm{C}$ to $750{ }^{\circ} \mathrm{C}$ with a heating rate of $15{ }^{\circ} \mathrm{C} / \mathrm{min}$ using Netzsch STA 449F1 analyzer. For the electrical measurements, platinum electrodes of $0.5 \mathrm{~cm}^{2}$ area were sputtered on the polished samples. Impedance measurements were carried out in the frequency range from $1 \mathrm{mHz}$ to $1 \mathrm{MHz}$ with the $\mathrm{AC}$ voltage of $3 \mathrm{~V}_{\mathrm{rms}}$ in the temperature range of $350{ }^{\circ} \mathrm{C}$ to $450{ }^{\circ} \mathrm{C}$ using the Novocontrol Concept 40 broadband dielectric spectrometer. Such a high voltage amplitude was caused by the low level of observed conductivity and it was necessary to obtain reliable results. However, it has not influenced the stability of the samples. The temperature range of IS measurement was determined by two factors: measurement range of the spectrometer (which precludes measurement above $10 \mathrm{M} \Omega$ ) and the temperature of glass crystallization. For the electrical measurements the measuring cell (schematically shown in Fig. 2), capable of supplying various gases on both sides, was used.

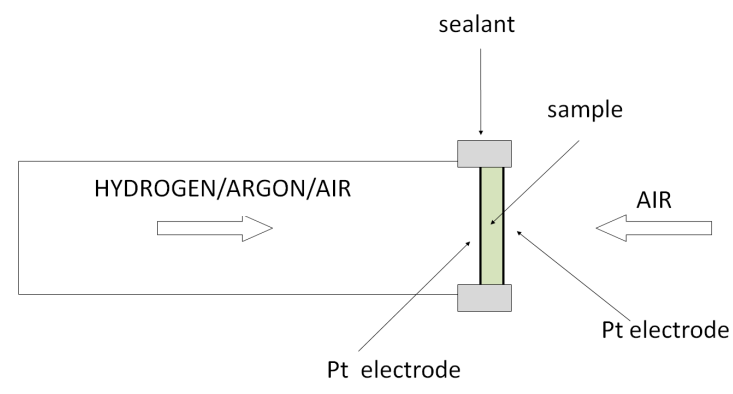

Fig. 2. The scheme of the measuring cell.

Such configuration of the measuring system was designed to avoid measurement of reduced metal layer. On one side, the air was supplied and, 
on the other side, the other gas (hydrogen, argon or air) was delivered. The gas supply system allowed us to change the humidity of the fed gases. In order to avoid gas leakage, the cell was sealed by a dielectric paste ESL 4606. Admittedly, such a system did not provide equilibrium of the electrochemical gradients, especially at high partial pressure of oxygen. However, it enabled us to observe the changes in conductivity while minimizing the reduction process on the surface of the glass.

\section{Results and discussion}

The XRD plot obtained for as-prepared 50PbO$50 \mathrm{SiO}_{2}$ glass is shown in Fig. 3. It consists of a 'halo pattern' which is characteristic of amorphous or highly disordered structures. This result is representative for all investigated compositions of glasses.

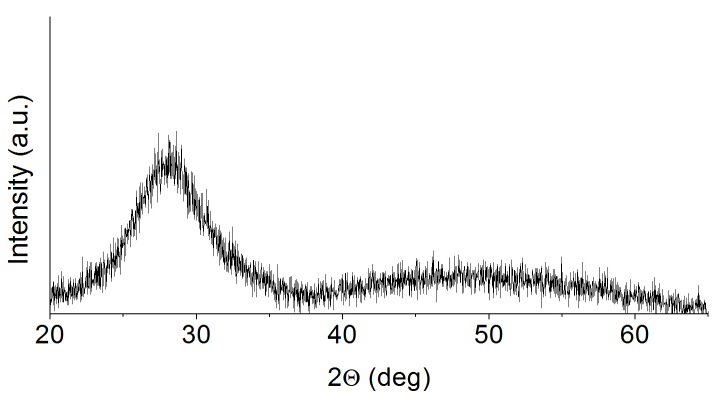

Fig. 3. The XRD plot of as-prepared lead-silicate glass.

The result of DSC analysis obtained for leadsilicate glass is presented in Fig. 4. As for XRD plot, this result is also representative for both investigated compositions. It is typical of amorphous structures, because some characteristic peaks can be found. The first peak refers to an endothermic process called glass transition. Thus, a temperature of the glass transition $\left(\mathrm{T}_{\mathrm{g}}\right)$ was determined. It was $445{ }^{\circ} \mathrm{C}$ and $433{ }^{\circ} \mathrm{C}$ for bismuth and lead silica glasses, respectively. The second peak in DSC plot refers to the exothermic crystallization process $\left(T_{c}\right)$. The last peak indicates the endothermic process of glass melting. The temperature of melting $\left(\mathrm{T}_{\mathrm{m}}\right)$ was determined as $756{ }^{\circ} \mathrm{C}$ and $712{ }^{\circ} \mathrm{C}$ for $33 \mathrm{Bi}_{2} \mathrm{O}_{3}-67 \mathrm{SiO}_{2}$ and $50 \mathrm{PbO}-50 \mathrm{SiO}_{2}$ glasses, respectively.

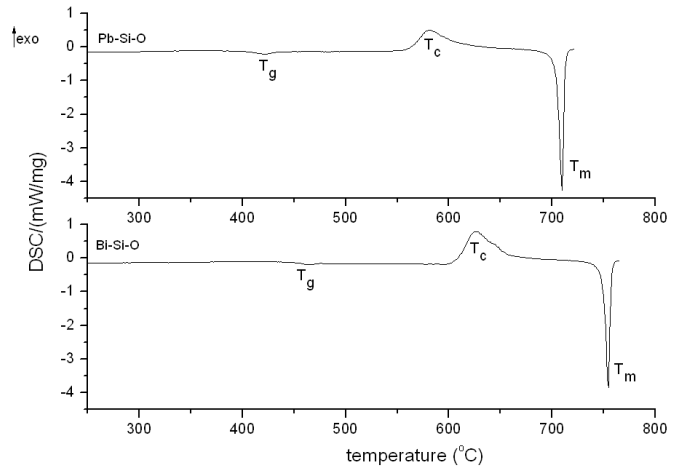

Fig. 4. The DSC plots of lead-silicate glasses (upper plot) and bismuth-silicate glasses (lower plot).

The results of impedance measurements in a form of Nyquist plots obtained for bismuth and lead-silicate glasses measured in various atmospheres at $400{ }^{\circ} \mathrm{C}$ are shown in Fig. 5a and Fig. 5b. These plots may suggest different nature of the processes for each sample. The glass $\mathrm{Bi}-\mathrm{Si}-\mathrm{O}$ behaves in a typical manner (Fig. 5a) - one can observe a clear semicircle, characteristic of the ionic conductivity behavior.

A slight increase in the resistance value with a decrease of oxygen partial pressure on the one side may be a result of a decrease in the number of available charge carriers. It can be assumed that in the case of bismuth silicate glasses there is only one type of charge carriers: oxygen ions. The obtained activation energy of this process, $1.31 \mathrm{eV}$, is in agreement with the paper of Kusz et al. [3] in which the authors describe conduction process of oxygen ions with activation energy $1.29 \mathrm{eV}$ for bismuth silicate glasses of similar composition. The situation is quite different in the case of $\mathrm{Pb}-\mathrm{Si}-\mathrm{O}$ glass. As shown in Fig. 5b, the change of the resistance values depending on the oxygen partial pressure in the interior of measuring cell is clearly visible. Moreover, the shape of the Nyquist plots also changes. With a decrease of oxygen amount, a second semicircle becomes visible. Thus, it can be suggested that in the case of lead-silicate glasses we are dealing with more than one electric conductivity processes. First mechanism is the conductivity of oxygen ions. The second one, according to Abe et al. [17], can be 

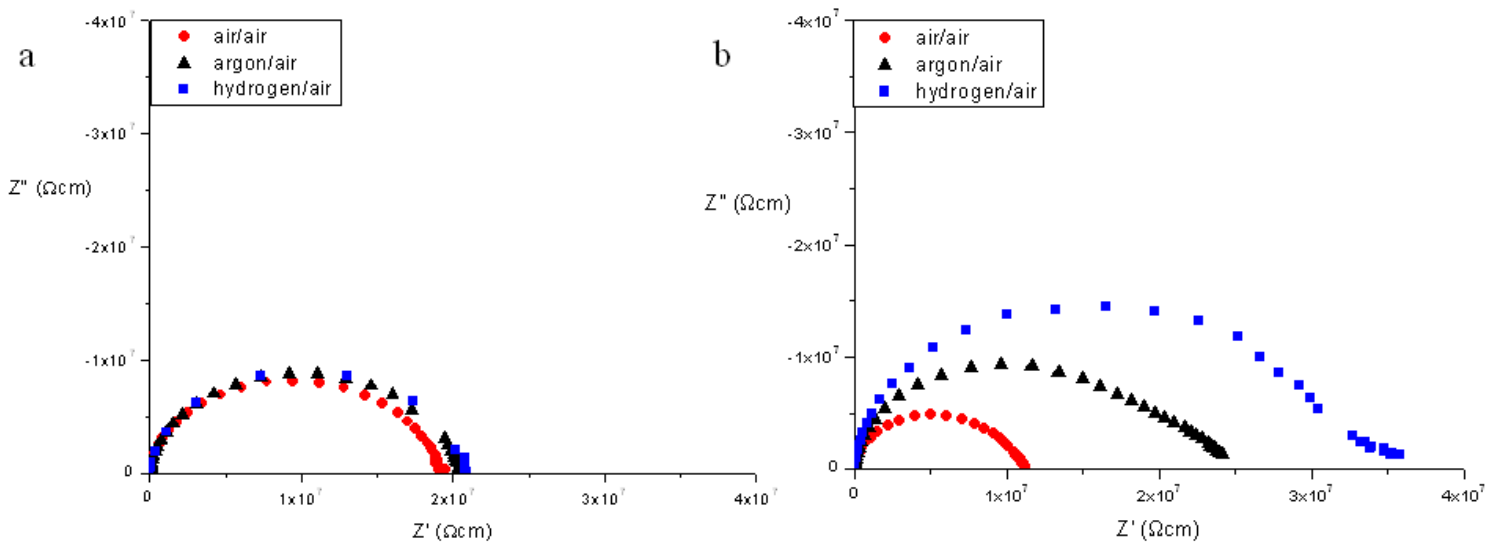

Fig. 5. The Nyquist plots of bismuth silicate (a) and lead silicate (b) glasses measured in different atmospheres at $400{ }^{\circ} \mathrm{C}$.

interpreted as proton conductivity. To verify this hypothesis, measurements in various gas humidity were performed. Fig. 6 shows the Arrhenius plots of electrical conductivity. Also the activation energies of electrical conductivity are assigned to each plot. The lowest activation energy was found for the sample measured in the atmospheres that could become a source of protons: hydrogen $(1.12 \pm 0.05) \mathrm{eV}$ and wet $\operatorname{argon}(1.15 \pm 0.05) \mathrm{eV}$. Activation energies of glasses measured in oxygen and in dry argon are higher and have values equal to $\mathrm{E}_{\mathrm{a}}=1.27 \mathrm{eV}$ and $\mathrm{E}_{\mathrm{a}}=1.34 \mathrm{eV}$, respectively. The measured data of electrical conductivity for each sample correspond with the results shown in Fig. 6. In the case of dry gases the value of electrical conductivity decreases with a decreasing oxygen partial pressure. In contrast, the level of electrical conductivity measured in wet argon (wAr in Fig. 6) coincides with the level of conductivity in dry air.

We suggest that this may be caused by protons taking a role of charge carriers and occupying the conducting path for oxygen ions. Then, the number of charge carriers is no longer limiting the process of electrical conductivity. Therefore, a hypothesis may be taken that both the transport of oxygen ions and protons take place along the same paths of conduction. According to Abe and Takahasi [24] the process of proton conductivity in glasses takes place among oxygen vacancies. The same defects

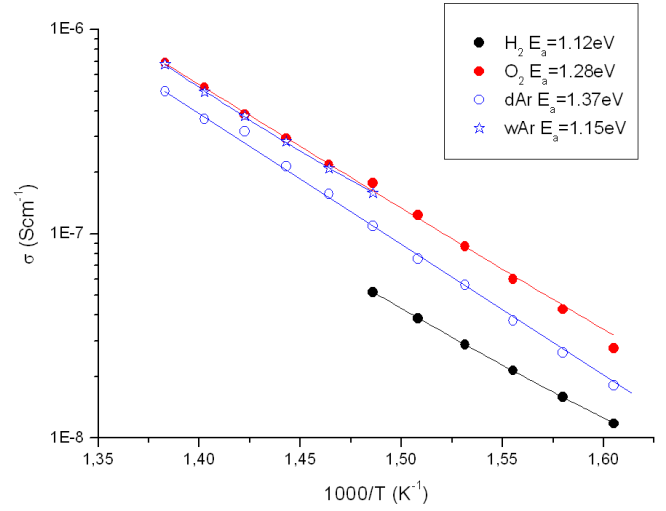

Fig. 6. The Arrhenius plots of electric conductivity for lead-silicate glasses measured in different atmospheres. Abbreviations dAr and wAr refer to dry argon and wet argon, respectively. Solid lines correspond to fitted data.

are also responsible for oxygen conductivity. Thus, these two processes should be treated as parallel phenomena. On the basis of these observations, the impedance spectrum obtained for lead-silicate glass measured in argon/air atmospheres was compared to the equivalent circuit shown in Fig. 7.

Two parallel processes of ionic conductivity are assumed $\left(R_{1}\right.$ related to the conductivity of oxygen ions and $\mathrm{R}_{2}$ related to the conductivity of protons). Another assumption is that all electrode resistances are low compared with the resistances 


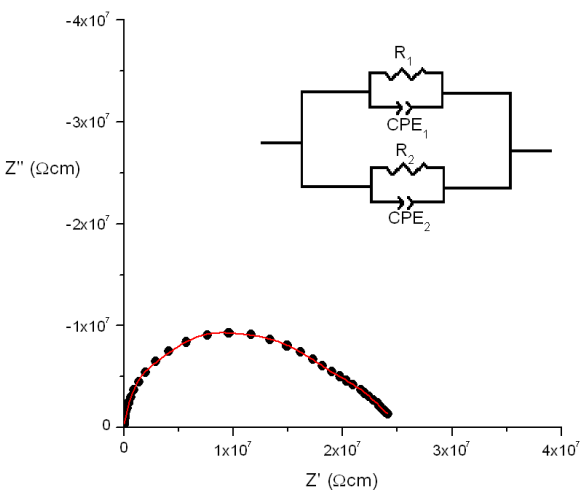

Fig. 7. The Nyquist plot of lead-silicate glass measured in argon and an equivalent circuit used to fit the parameters. Solid lines correspond to linear fitted data.

of the processes of charge transport and can be neglected in further consideration. The fitting results of separation of the ionic conductivity components in lead-silicate glasses measured in argon are shown in Fig. 8.

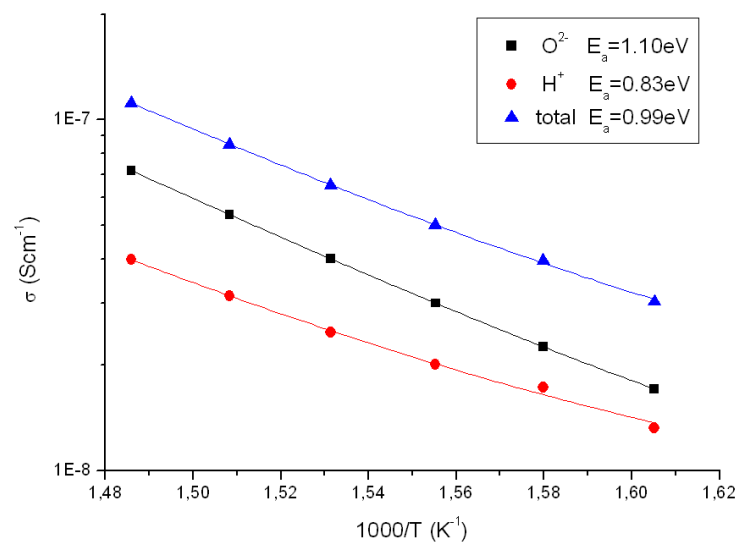

Fig. 8. Fitting results of ionic conductivity components separation performed for lead-silicate glass measured in argon. Solid lines correspond to the fitted data.

The obtained activation energies correspond to the literature regarding the oxygen and protons transport processes in oxide glasses [25]. On the basis of the results presented in Fig. 8 it can be stated that at high temperature, the contribution of proton conductivity is about 30 percent of the total conductivity. Due to the low value of the activation energy of proton ion transport processes, the proton conductivity achieves the level of oxygen ions at the lower temperature.

\section{Conclusions}

Comparison of the results of impedance spectroscopy measurements in lead silicate and bismuth silicate glasses suggests two different conduction mechanisms. In the case of bismuth silicate glass, we have to deal with pure ionic conductivity with oxygen ions as charge carriers. The level of electrical conductivity of this glass was $5 \times 10^{-8} \mathrm{~S} \cdot \mathrm{cm}^{-1}$ at $400{ }^{\circ} \mathrm{C}$, with a typical activation energy for the process of oxygen conductivity of about $1.3 \mathrm{eV}$. The value of electrical conductivity of bismuth silicate was independent of measuring atmosphere. In the case of lead silicate glasses the electrical conductivity at $400{ }^{\circ} \mathrm{C}$ was slightly higher $\left(1.7 \times 10^{-7} \mathrm{~S} \cdot \mathrm{cm}^{-1}\right)$ in air, but decreased with a decrease of oxygen partial pressure down to $6 \times 10^{-8} \mathrm{~S} \cdot \mathrm{cm}^{-1}$ in hydrogen. Two types of charge carriers: oxygen ions and protons ion were postulated. We managed to separate the components of ionic conductivity in lead silicate glasses. Proton conductivity measured in wet argon at $400{ }^{\circ} \mathrm{C}$ was estimated to be $4 \times 10^{-8} \mathrm{~S} \cdot \mathrm{cm}^{-1}$ while the oxygen ions conductivity was $7 \times 10^{-8} \mathrm{~S} \cdot \mathrm{cm}^{-1}$. Lower activation energy of proton ion transport process led to a decrease in the activation energy of the conduction process in atmospheres containing a proton ions source. We suggest that both types of charge carriers are transported along the same conduction paths using oxygen defects in the glass structure.

\section{Acknowledgements}

This work was supported by the National Science Center under the grant No. NCN 2012/05/B/ST3/02816.

\section{References}

[1] Kohara S., Ohno H., Takata M., Usuki T., Morita H., Suzuya K., Akola J., Pusztai L., Phys. Rev. B, 82 (2010), 134209.

[2] Warrel C.A., Henshall T., J. Non-Cryst. Solids, 29 (1978), 283.

[3] Kusz B., Trzebiatowki K., Barczyński R.J., Solid State Ionics, 159 (2003), 293

[4] LiU L., Z. Phys. B 90 (1993), 393. 
[5] Wang P.W., Zhang L.P., J. Non-Cryst. Solids, 194 (1996), 129.

[6] Witkowska A., Rybicki J., Di Cicco A., J. NonCryst. Solids, 351 (2005), 380.

[7] Kusz B., Optica Applicata 33 (2003), 141.

[8] Gackowska J., Gazda M., Trzebiatowski K., Kusz B., J. Non-Cryst. Solids, 354 (2008), 4319.

[9] Łączka M., Stoch L., Górecki J., J. Alloys and Compounds, 186 (1992), 279.

[10] Stepien R., Pysz D., Kujawa I., Buczynski R., Optical Materials, 35 (2013), 1587.

[11] Kusz B., Trzebiatowski K., Gazda M., MURAWSKI L., J. Non-Cryst. Solids, 319 (2003), 137.

[12] Hughes K., Isard J.O., Milnes G.C., Phys. Chem. Glasses, 9 (1968), 43.

[13] Strauss S.W., Moore D.G., Harrison W.N., Richards L.E., J. Res. Nat. Bur. Stand., 56 (1956), 135.

[14] Mendiratta S.K., Phys. Stat. Sol.(A), 93 (1986), 293.

[15] El-Bayoumi O.H., MacCrone R.K., J. American Ceramic Society, 59 (1976), 386.

[16] Milnes G.C., Isard J.O., Phys. Chem. Glasses, 3 (1962), 157.

[17] Aвe Y., Hosons H., Hikichi Y., J. Materials Science Letters, 9 (1990), 1443.
[18] Pavlova G.A., Izvest. Vysshykh Ucheb. Zavedenii Khim. i Khina. Teknol, 5 (1958), 82.

[19] Bochentyn B., WARYCH A., SZREder N., MIELEWCZYK-GRYŃ A., KARCZEWSKI J., PrześniaK-Welenc M., Gazda M., Kusz B., J. Non-Cryst. Solids, 439 (2016), 51.

[20] Bochentyn B., Karczewski J., Miruszewski T., KUsz B., J. Alloys and Compounds, 646 (2015), 1124.

[21] Kusz B., Miruszewski T., Bochentyn B., ŁAPIŃSKI M., KARCZEWSKI J., J. Electron. Mater., 45 (2016), 1085.

[22] Bochentyn B., Karczewski J., Miruszewski T., Kusz B., Mat. Chem. Phys., 177 (2016), 353.

[23] Bochentyn B., Karczewski J., Miruszewski T., Kusz B., Mater. Res. Bull., 76 (2016), 195.

[24] Aвe Y., Takahasi M., Chem. Phys. Lett., 411 (2005), 302.

[25] Aвe Y., Hosono H., Оhta Y., Phys. Rev. B, 38 (1988), 10166.

Received 2015-10-22

Accepted 2017-11-21 